ANL/PP -71021

DE92 003420

\title{
XENON-129 NMR STUDY OF THE MICROPOROUS STRUCTURE OF CLAYS AND PIILARED CLAYS
}

\author{
Chihji Tsiao, Kathleen A. Carrado, \\ and Robert E. Botto*
}

Chemistry Division Argonne National Laboratory Argonne, IL 60439

\section{DISCLAIMER}

\begin{abstract}
This report was prepared as an account of work sponsored by an agency of the United States Government. Neither the United States Government nor any agency thereof, nor any of their employees, makes any warranty, express or implied, or assumes any legal liability or responsibility for the accuracy, completeness, or usefulness of any information, apparatus, product, or process disclosed, or represents that its use would not infringe privately owned rights. Reference herein to any specific commercial product, process, or service by trade name, trademark, manufacturei, or otherwise does not necessarily constitute or imply its endorsement, recommendation, or favoring by the United States Government or any agency thereof. The views and opinions of authors expressed herein do not necessarily state or reflect those of the United States Government or any agency thereof.
\end{abstract}

DISTRIBUTION OF T, IS DOCUMENT IS UNLIRITEB

*Author to whom correspondence should be addressed. 


\section{ABSTRACT}

${ }^{120} \mathrm{Xe}$ NMR studies have been carried out using xenon gas adsorbed in clays and pillared clays. Data from the measurements provide information on the pore structure of clays before and after pillaring. The results indicate that the effective pore diameter of montmorillonite increases, for example, from $5.4 \dot{A}$ to $8.0 \AA$ after pillaring cheto-montmorillonite with aluminum polyoxohydroxy Keggin cations. The data are consistent with X-ray powder diffraction results, which show a corresponding increase in the interlamellar gallery height from 5.6 $\dot{A}$ to $8.4 \AA$.

\section{INTRODUCTION}

Smectite clays comprise a class of aluminosilicates that are composed of a layered structure in which two silicate sheets sandwich a central aluminumcontaining sheet. ${ }^{12,3}$ The aluminum cations are bonded to an octahedral arrangement of oxygen aniors, and repetition of these $\mathrm{AlO}_{6}$ units in two dimensions forms the octahedral layer. Similarly, a tetrahedral layer is formed from $\mathrm{SiO}_{4}$ silicate units. The parallel layers in these structures are held together by electrostatic forces, and can be expanded by penetration of polar species between the clay layers. The preparation of pillared interlayered clays is based on this characteristic of swelling. Generally, organic or inorganic cation complexes are used to replace the exchangeable cations (e.g. $\mathrm{Na}^{+}, \mathrm{Ca}^{2+}$ ) from the interlayer regions and hold the sheets apart by acting as props or supports. By varying the size, charge and shape of the entering ions, a homogeneous network of nicropores can he obtained with pore openings ${ }^{2}$ ranging from $4 \dot{A}$ to $18 \dot{A}$. The distances between adjacent pairs of homogeneously distributed cations are sufficient to allow the penetration of large molecules into the permanent 
interlayer pore system thus created. Clays have long been used as catalysts and catalyst supports, ${ }^{45}$ and recent advances in the intercalation chemistry of pillared interlayered clays ${ }^{6}$ has renewed interest in clays as catalysts in cracking of heavy residual crude oil ${ }^{7,8}$ and in simulation of coal formation. ${ }^{9,10}$

${ }^{120} \mathrm{Xe}$ NMR spectroscopy has proved to be a sensitive and convenient technique for investigating the structural properties of zeolites ${ }^{11,12,13}$. The method has the following advantages: xenon is a monatomic gas having a large Van der Waals radius $(2.2 \AA)$ and is chemically inert. Any small perturbations on its large, polarizable electron cloud are transmitted directly to the nuclear environment, and this is responsible for the large observed range of ${ }^{120} \mathrm{Xe}$ chemical shifts. In addition, ${ }^{120} \mathrm{Xe}$ has nuclear spin of $1 / 2$ and its NMR receptivity is 32 times greater than ${ }^{13} \mathrm{C},{ }^{14}$ which means that ${ }^{120} \mathrm{Xe}$ is substantially easier to observe than ${ }^{13} \mathrm{C}$ under similar conditions. While the spin-lattice relaxation time $\left(\mathrm{T}_{1}\right)$ of xenon gas is extremely long ( $10^{6}$ seconds), ${ }^{15}$ xenon atoms adsorbed in the cavities of microporous materials show a greatly reduced $T_{1}$ owing to enhanced xenon-xenon collisions and collisions between xenon and the pore "wall". This facilitates the detection of xenon surbed in micropores $(<20 \dot{A})$ on the basis of relaxation time differences. In this investigation, we focus on ${ }^{120} \mathrm{Xe}$ NMR spectroscopy of xenon gas sorbed in two different clay minerals and their pillared interlayered counterparts.

\section{EXPERIMENTAL}

The clay samples used in this work are $\mathrm{SAz}-1$, a $\mathrm{Ca}^{2+}-$ montmorillonite from Arizona (known as cheto), which was obtained from the Source Clay Repository, Columbia, MO, and Bentolite $\mathrm{L}, \mathrm{a} \mathrm{Ca}^{2+}$ - bentonite (referred to as bentonite) specially treated to remove all but $0.28 \mathrm{Fe}$, which is supplied by 
ECC America Inc., TX, a Southern Clay Products subsidiary. The aluminum-hydroxy polymer solution used is marketed by the Reheis Chemical Co. under the trade name of Chlorhydrol. The pillaring cation in this solution is believed ${ }^{16}$ to be $\left[\mathrm{Al}_{13} \mathrm{O}_{4}(\mathrm{OH})_{24}\left(\mathrm{H}_{2} \mathrm{O}\right)_{12}\right]^{7+}$. Pillaring experiments were carried out by adding $1 \mathrm{ml} /(\mathrm{g}$ clay) of pillaring solution to a slurry of 0.5 wto clay in distilled deionized water (DDW). For example, $20 \mathrm{~g}$ of bentonite were slurried in $1.8 \mathrm{~L}$ DDW with a mechanical stirrer and heated to $65^{\circ} \mathrm{C}$. To this was added a freshly diluted sample of $20 \mathrm{ml}$ chlorhydrol in $200 \mathrm{ml} \mathrm{DDW}$, and the slurry was stirred at $65^{\circ} \mathrm{C}$ for $1.5 \mathrm{hr}$; the $\mathrm{pH}$ was kept near 5.5 by adding dilute $\mathrm{NH}_{4} \mathrm{OH}$. Pillared clays were dried overnight at $110^{\circ} \mathrm{C}$ and then calcined at $400^{\circ} \mathrm{C}$ in air for 4 hours; they are denoted as p-bentonite and p-cheto.

$X$-ray powder diffraction was done on a Scintag PAD-V instrument using $C u$ $\mathrm{K} \alpha$ radiation and a hyperpure germanium solid-state detector at a scan rate of $0.5^{\circ} 2 \theta / \mathrm{min}$; powders were contained in horizontally-held trays. The instrument was calibrated to the (101) reflection of low-quartz at $3.34 \dot{A}$. Data was collected on a DG desktop computer system.

NMR measurements were carried out by placing approximately 0.4 gram of sample into an NMR test ture having a sealable J. Young stopcock. A vacuum manifold was used for outgassing the sample to an ultimate pressure of $1 \times 10^{-5}$ torr. Prior to xenon adsorption, the clays were slowly heated to $100^{\circ} \mathrm{C}$ over 2 hours, or to $400^{\circ} \mathrm{C}$ over 6 hours for pillared clays, and maintained at each of these respective temperatures overnight under vacuum to completely remove water. After the samples were allowed to cool to room temperature, xenon gas was introduced and allowed to equilibrate for 10-15 minutes. The sample tube then was sealed and removed from the manifold to carry out the NMR measurements. The uptake of xenon gas adsorbed in the clay was recorded in torr by a digital 
vacuum-meter Telvac II (Fredericks Co.). Xenon adsorption isotherms were measured at room temperature during this process and showed a Langmuir-type dependence of xenon pressure below 800 torr.

All ${ }^{10} \mathrm{Xe}$ NMR spectra were recorded using a Bruker AM 300 spectrometer operating at $83.02 \mathrm{MHz}\left(7.0\right.$ Tesla) with a recycle delay of 0.5 second and $90^{\circ}$ pulse width of $9.8 \mu$ seconds. Each spectrum is the accumulation of 8,000 transients. The chemical shift was reported with reference to the extrapolated shift of bulk xenon at $P=0$. Deshielded (downfield) xenon chemical shifts are considered positive.

\section{RESULTS AND DISCUSSION}

Figure 1 shows the $\mathrm{x}$-ray powder diffraction (XRD) spectra of clays used in this study. The most prominent and diagnostic peak is the (001) reflection, or d-spacing, along the c-axis. This d-spacing includes the height of the clay layer (about $9.6 \dot{A}$ ) and the interlamellar, or gallery, space. The d-spacing increases from $15.2 \dot{A}$ to $18.3 \dot{A}$ when bentonite is pillared with alumina (Fig. $1 a \& 1 b)$. The spectrum for unpillared cheto is nearly identical to that of unpillared bentonice: both clays contain $\mathrm{Ca}^{2+}$ as the exchangeable cation, hence the d-spacings are the same. Bentonites are primarily pure montmorillonite, but they rarely contain less than $10 \%$ nonclay minerals. Cristobalite is frequenty present and is intimately mixed with the clay mineral when the particle size is $\sim 1 \mu \mathrm{m},{ }^{17}$ which is the particle size of this bentolite. Cristobalite therefore appears in the XRD patterns of bentonites and not in those for cheto.

Figure 2 shows the Langmuir-type isotherms for xenon gas in clay and pillared clay samples at $21^{\circ} \mathrm{C}$. Xenon uptake is very low for bentonite even at pressures up to 800 torr; however, xenon uptake increases markedly for 
p-bentonite and p-cheto. This indicates that the free volumes of the pores expand after pillaring. Figure 3 is a compilation of NMR spectra of xenon adsorbed on p-bentonite at various xenon pressures. The ${ }^{129} \mathrm{Xe}$ resonance at 0.0 ppm in each spectrum can be assigned to xenon gas that is adsorbed on the surface of the clay particles. This resonance is used as a secondary chemical shift reference. The chemical shifts of the prominant downfield peak in the spectra increase with the xenon pressure, and is consistent with the deshielding effect expected for enhanced xenon-xenon collision frequencies at higher xenon density. Figure 4 illustrates plots of ${ }^{120} \mathrm{Xe}$ chemical shifts versus xenon density for the various clay samples. No ${ }^{129} \mathrm{Xe}$ resonance was observed for bentonite, since xenon uptake was extremely low for this sample.

The NMR chemical shift of xenon adsorbed in a rigid inorganic matrix may be expressed by the Fraissard equation; 18,19.20 this includes several terms, each of which characterizes an interaction that a xenon atom can experience:

$$
\delta(\rho)=\delta_{0}+\delta_{1} \rho+\delta_{2} \rho^{2}+\delta_{\mathbf{E}} \rho^{-1}
$$

where $\rho$ is the xenon density in atoms per gram of dry sample; $\delta(\rho)$ is the chemical shift of xenon gas relative to the bulk gas at $\rho=0 ; \delta_{0}$ is a term characteristic of interactions between xenon and the "wall"; $\delta_{1}$ and $\delta_{2}$ are coefficients describing the effect of two-body and three-body xenon-xenon collisions, respectively; and $\delta_{E}$ is the electrostatic field term. In the case of $\mathrm{Ca}^{2+}$-substituted clays and pillared clay samples, the electrostatic field effect should be negligible $\left(\delta_{E}-0\right) .{ }^{21}$ Also, because the channel diameter is small, three-body collisions are impossible and $\delta_{2}=0$. Thus, Eq. 1 reduces to:

$$
\delta(\rho)=\delta_{0}+\delta_{1} \rho
$$


The experimental data fit well to Eq. 2 as is shown in Fig. 3. Calculated chemical shift parameters, $\delta_{0}$ and $\delta_{1}$ are listed in Table 1 . In general, $\delta_{0}$, which is obtained by extrapolation of the chemical shift to zero xenon density, can be considered characteristic of the pore structure. Demarquay and Fraissard ${ }^{22}$ were able to establish an empirical relationship for the dependence of $\delta_{0}$ on the mean free path, $\dot{L}$, of xenon in the void space of zeolite materials using the following equation:

$$
\delta_{0}=243 \times[2.054 /(2.054+\dot{L})]
$$

The two-dimensional network of micropores in pillared interlayered clays can be considered a series of interconnecting tubular channels. Hence a relationship between the mean free path and the effective diameter $\left(D_{\text {eff }}\right)$ for a channel structure can be defined by ${ }^{2 l}$

$$
\dot{\mathrm{L}}=\mathrm{D}_{\mathrm{eff}}-\mathrm{D}_{\mathrm{Xe}}
$$

where $D_{x e}$ is the diameter of a xenon atom $(4.4 \dot{A})$. The calculated values of $\dot{L}$ and the effective pore diameters of the clay samples are presented in Table 2 . The ${ }^{10} \mathrm{Xe}$ NMR data for cheto shows that the effective diameter of the channel network increases from $5.4 \AA$ to $8.0 \AA$ after pillaring with aluminum Keggin ions. This correlates well with XRD results, which give interlamellar gallery heights of $5.6 \AA$ for the $\mathrm{Ca}^{2+}$-clay and $8.4 \AA$ when the $\mathrm{Ca}^{2+}$ ions are replaced by alumina pillars. The effective pore diameter of $p$-bentonite is larger than that of $\mathrm{p}$-cheto at $8.7 \dot{\mathrm{A}}$. The excellent agreement with $\mathrm{x}$-ray diffraction data shows that 
${ }^{120} \mathrm{Xe}$ NMR spectroscopy is a viable technique for monitoring the microporous structures in clays.

\section{ACKNOWLEDGEMENT}

This work was performed under the auspices of the Office of Basic Energy

Sciences, Division of Chemical Sciences, U.S. Department of Energy, under contract number W-31-109-ENG-38. 
Table 1. The chemical-shift parameters for Fraissard equation for the various clay samples.

\begin{tabular}{lcc}
\hline Sample & $\delta_{0}(\mathrm{ppm})$ & $10^{20} \delta_{1}$ \\
& $\mathrm{ppm}$ g/atom \\
\hline cheto & \\
p-cheto & $162.3 \pm 0.1$ & $6.53 \pm 0.16$ \\
bentonite & $88.9 \pm 0.4$ & $5.49 \pm 0.21$ \\
p-bentonite & - & - \\
\hline
\end{tabular}

1) cheto: $\mathrm{Ca}^{2+}$ - montmorillonite.

2) pillared clays 
Table 2. Mean free path, $\bar{L}$, and effective diameter of the channel, $D_{\text {eff }}$, for the various clay samples.

\begin{tabular}{lcc}
\hline Sample & $\overline{\mathrm{L}}(\dot{\mathrm{A}})$ & $\mathrm{D}_{\text {ell }}(\dot{\mathrm{A}})$ \\
\hline cheto & $1.0 \pm 0.1$ & $5.4 \pm 0.2$ \\
p-cheto & & $8.0 \pm 0.4$ \\
bentonite & $3.6 \pm 0.2$ & - \\
p-bentonite & $4.3 \pm 0.2$ & $8.7 \pm 0.4$ \\
\hline
\end{tabular}

1) cheto: $\mathrm{Ca}^{2+}$ - montmorillonite.

2) pillared clays. 


\section{REFERENCES}

1. Pinnavaia, T. J. Science, 1983, 220, 4595.

2. Figueras, F. Catal. Rev. -Sci.\& Eng. 1988, 30(3), 457.

3. Barrer, R. M. J. Inclusion Phenomena, 1986, 4, 109.

4. Gates, B. C.; Katzer, J. R.; Schuit, G. C. Chemistry of Catalytic Processes, Mcgraw-Hill, New York, 1979.

5. Laszlo, P. Science, 1987, 235, 1473.

6. Vaughan, D. E. W. Catalysis Today, 1988, 2, 187.

7. Shabtai, J.; Lazar, R; Oblad, A. G. Stud. Surf. Sci. Catal. 7, (pt. B. New Horizons in Catalysis), $1981,828$.

8. Occelli, M. L. Ind. Eng. Chem. Prod. Res. Dev., 1985, 22, 553.

9. Hayatsu, R.; McBeth, R. L.; Scott, R. G.; Botto, R. E.; Winans, R. E. Org. Geochem., 1984, 6,463 .

10. Carrado, K. A.; Hayatsu, R.; Botto, R. E.; Winans, R. E. Clays and Clay Minerals, $1990, \underline{38(3)}, 250$.

11. Fraissard, J.; Ito, T. Zeolites, 1988, $\underline{8}, 350$.

12. Ripmeester, J. A. J.Am. Chem. Soc., 1982, 104, 289.

13. Scharpf, E. W. ; Crecely, R. W.; Gates, B. C.; Dybowski, C. R. J. Phys. Chem., $1986, \underline{90}, 9$.

14. Reisse, J. Nouv. J. Chem., 1986, 10, 665 .

15. Hunt, E. R.; Carr, H. Y. Phys. Rev., 1963, 130, 2302.

16. Occelli, M. L.; Tindwa, R. M. Clay Clay Miner., 1983, 31, 22.

17. Grim, R. E. in Clay Mineralogy, McGraw-Hill, New York, 1953, 362.

18. Ito, T.; Fraissard, J. in Proc. 5th Intern. Conf. Zeolites, 1980, 510.

19. Ito, T.; Fraissard, J. J. Chem. Phys., 1982, 76, 5225.

20. Ito, T.; Fraissard, T. J. Chem. Phys. Lett., 1984, 111, 271.

21. Ito, T.; Fraissard, J. J. Chem. Soc. Farad. Trans. I, 1987, 83, 451.

22. Demarquay, J.; Fraissard, J. Chem. Phys. Lett., 1987, 136, $314-318$. 
FIGURE CAPTIONS

Figure 1. X-ray powder diffraction spectra of (a) bentonite (b) pillared bentonite and (c) pillared cheto. The values of the d-spacings are indicated at the curved arrows; the straight arrows indicate the cristobalite impurity in the bentonite.

Figure 2. Isotherms of total xenon uptake on various clay samples. o bentonite; - cheto; $\square$ - pillared cheto; - pillared bentonite.

Figure 3. Xenon-129 NMR spectra of xenon adsorbed in p-bentonite as a runction of xenon pressure.

Figure 4. Plots of xenon chemical shift versus xenon density for the various clay samples. - - cheto; $\square$ - pillared cheto; - pillared bentonite. 


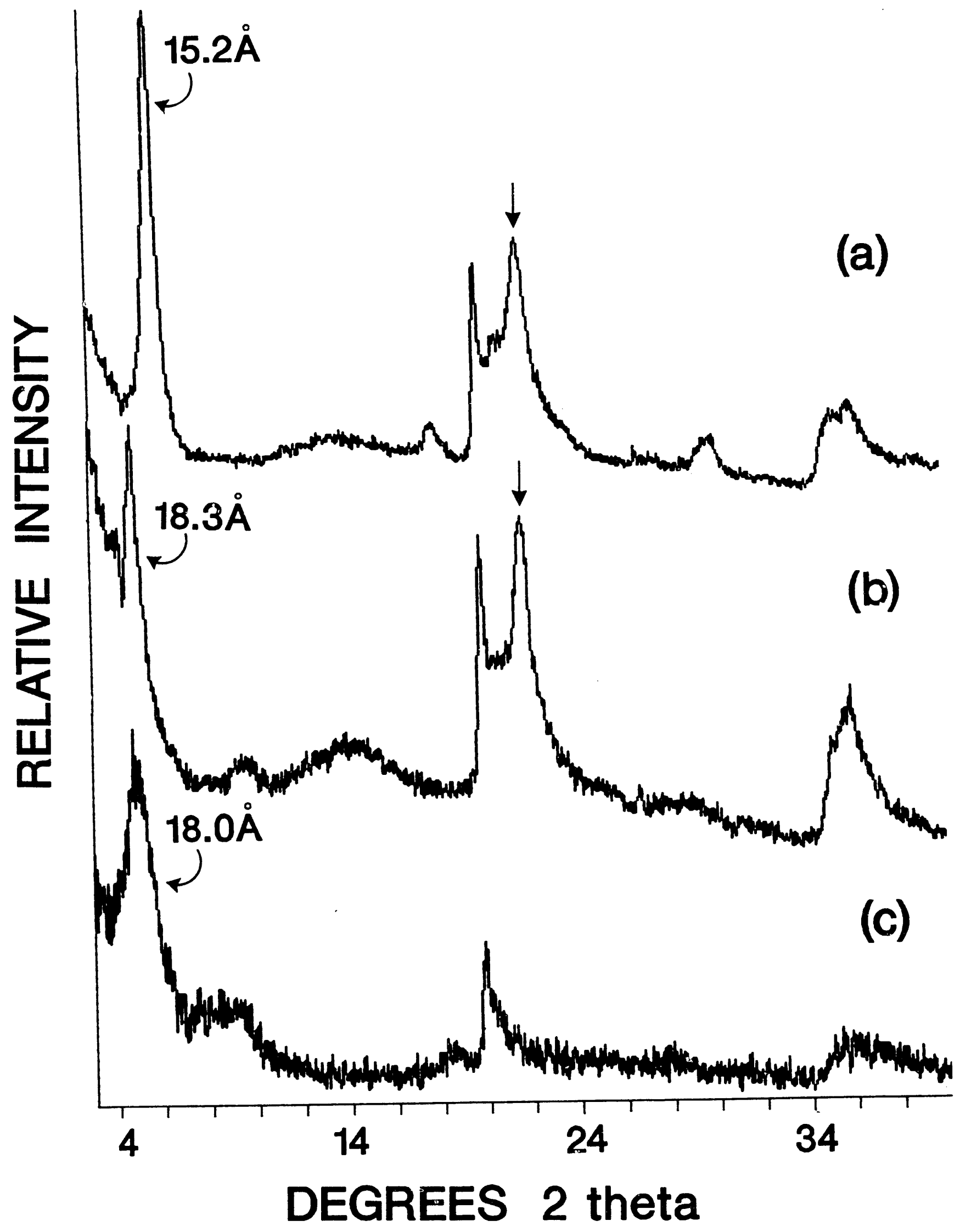




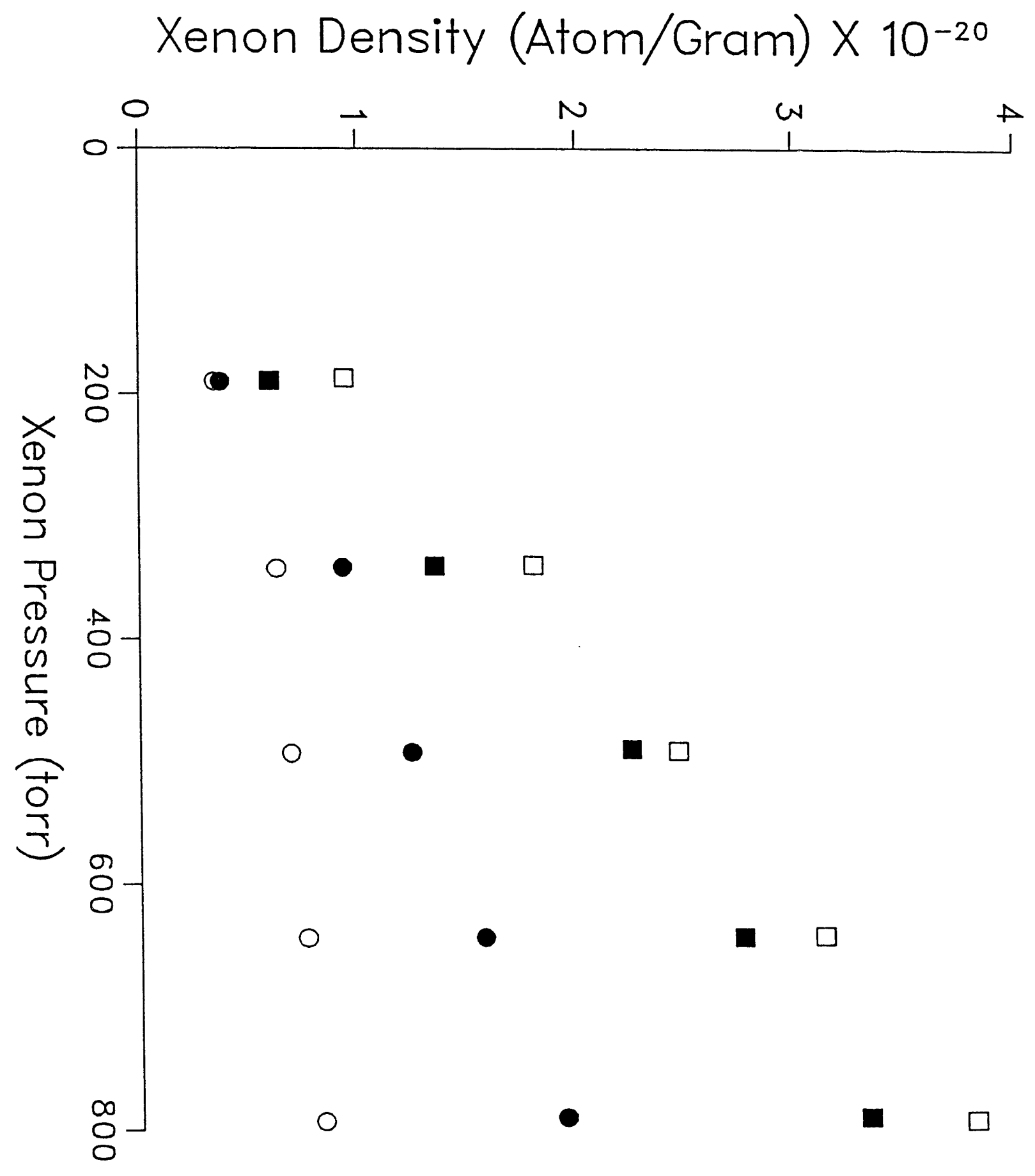




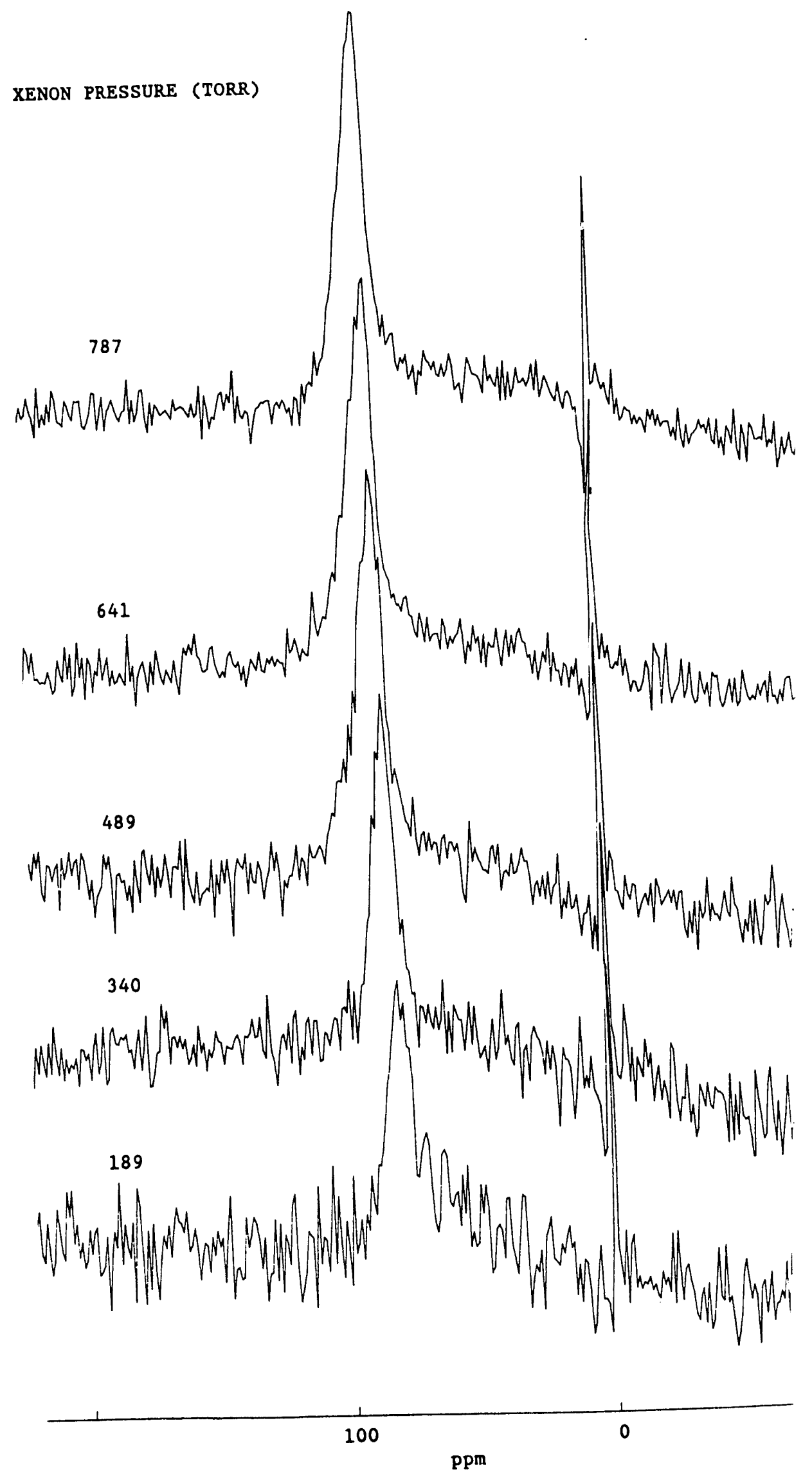




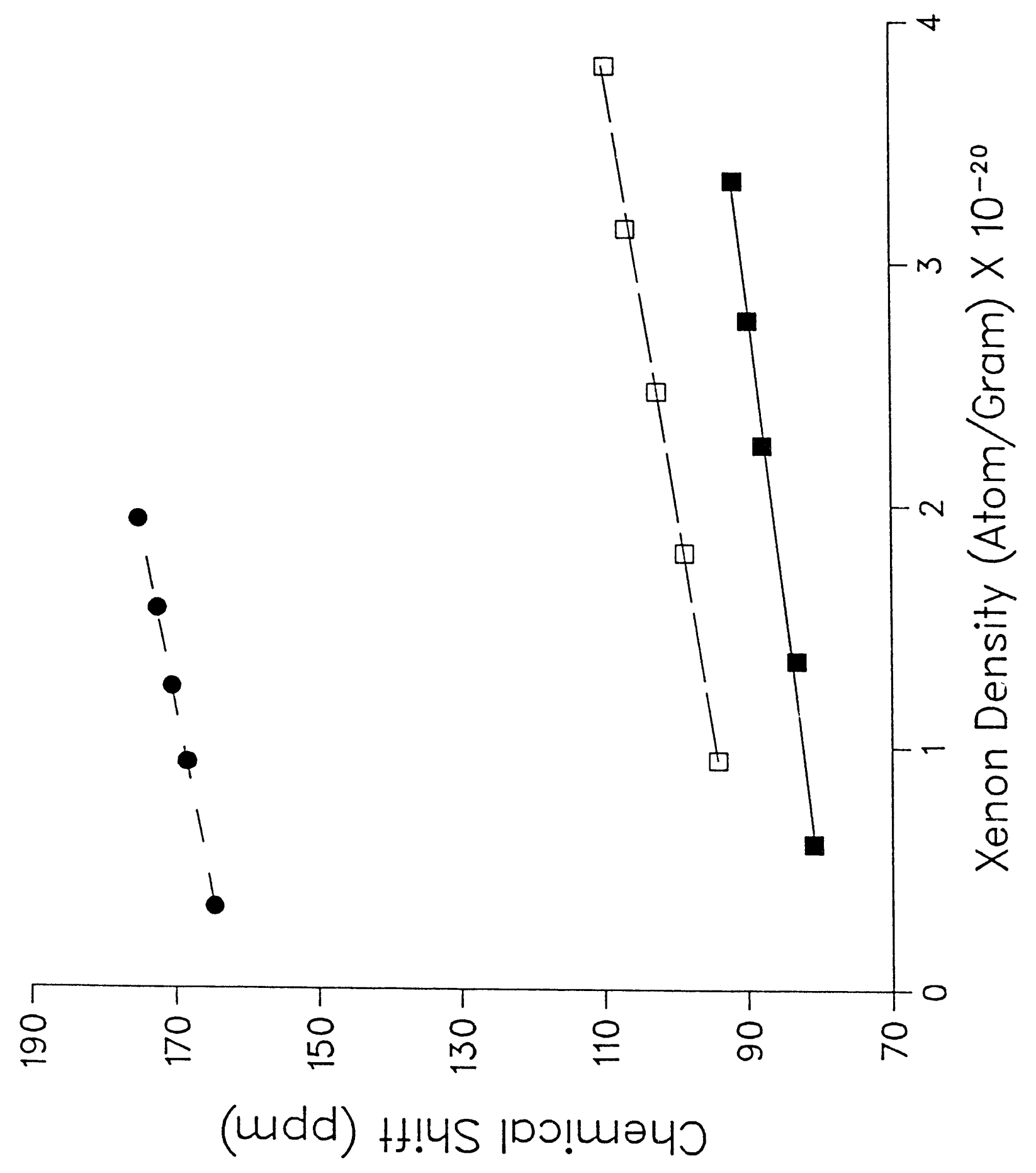



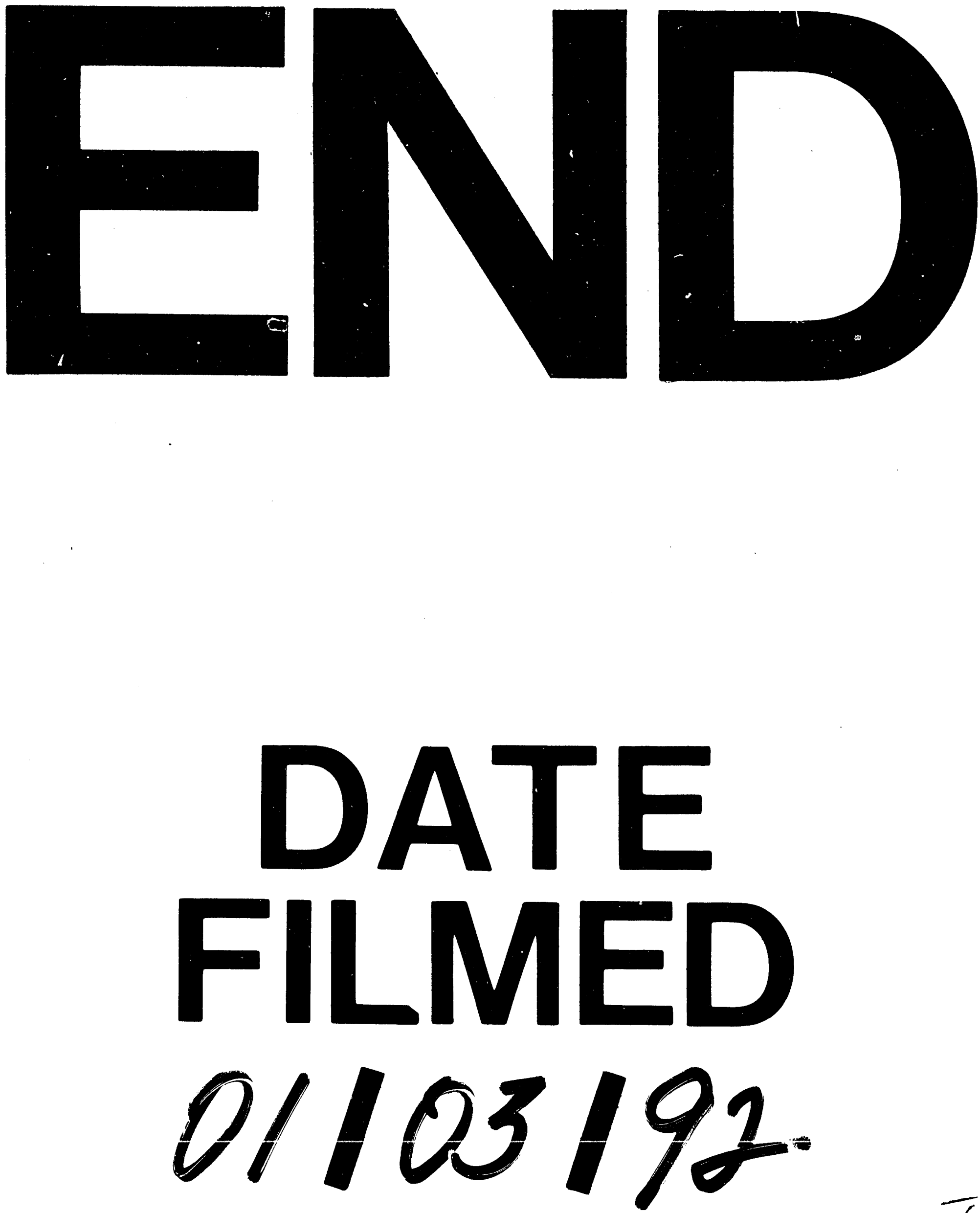
